Res Publica Revista de Historia de las Ideas Políticas

ISSN: $1131-558 \mathrm{X}$

\title{
Hermann Heller: la episteme sociológica como reelaboración democrática de la relación entre pluralismo social y Estado
}

\author{
Adrián Velázquez Ramírez
}

Recibido: 24-08-2020/ Aceptado: 25-04-2021

Resumen. El artículo explora las consecuencias que tiene el uso de la sociología en la filosofía política de Hermann Heller. Para Heller, el arribo histórico de la democracia social empuja hacia una renovación de la Teoría del Estado con el objetivo de proyectar formas de organización capaces de adaptarse al carácter plural y conflictivo de la sociedad política. Ante esta situación la "episteme sociológica" le permitió conectar de manera innovadora el Estado, la producción democrática del orden jurídico y el pluralismo social, asegurando con ello una instancia coordinadora de la solidaridad social. Dentro de este esquema, la sociología jurídica se presenta como un saber político central capaz de hacer inteligibles procesos de traducción de tendencias sociales en formas político-jurídicas.

Palabras clave: Heller; sociología; teoría del Estado; socialismo democrático.

\section{[en] Hermann Heller: the Sociological Episteme as a Democratic Reworking of the Relationship between Social Pluralism and the State.}

\begin{abstract}
The article explores the implications of the usage of sociology in Hermann Heller's political philosophy. For Heller, the arrival of social democracy was pushing towards a renewal of State Theory with the aim of projecting forms of organization capable of adapting to the plural and conflicting character of political society. In the face of this situation, the sociological episteme enabled him to connect in an innovative way the State, the democratic production of the legal order and social pluralism thus ensuring a coordinating instance of social solidarity. Within this scheme, sociology is presented as a central political knowledge capable of making intelligible the constant dynamics of transformation of social trends into legal forms.
\end{abstract}

Keywords: Heller; Sociology; State Theory; Democratic Socialism.

Sumario. 1. Introducción: el difícil nacimiento de lo sociopolítico. 2. El Estado social y la disputa por la frontera entre derecho y sociología. 3. El derecho entre el Estado y la sociedad. 4. La crisis de la forma política moderna y la alternativa sociológica. 5. La producción social y democrática del derecho. 6. La sociología jurídica como nueva razón de Estado. 7. Conclusiones. Bibliografía.

Cómo citar: Velázquez Ramírez, A. (2021). Hermann Heller: la episteme sociológica como reelaboración democrática de la relación entre pluralismo social y Estado. Res Publica. Revista de Historia de las Ideas Politicas, 24(2), 183-194.

\section{Introducción: el difícil nacimiento de lo sociopolítico}

El presente artículo se propone reconstruir el impacto que tuvo la sociología en el desarrollo de la filosofía política de Hermann Heller. Esta cuestión es de gran importancia pues en la elaboración de su dispositivo constitucional, la episteme sociológica funciona como el catalizador de una robusta y original reformulación en clave democrática de la relación entre Estado, derecho y pluralismo social ${ }^{2}$. Esto marcó un momento importante en la historia de la recepción de la sociología en la

\footnotetext{
Universidad Nacional de San Martín, Argentina.

adrian.velaram@gmail.com

Por episteme nos referimos a un principio de generación de un saber. Este aspecto generativo implica identificar una toma de posición -un punto de vista- que opera estableciendo una red de relaciones y premisas que permiten el surgimiento de una determinada modalidad de saber. En este sentido la episteme sociológica no refiere tanto a una elección disciplinar sino a un argumento general o hilo conductor que desde una posición singular (el punto de vista sociológico) le permite a Heller trazar relaciones entre los distintos ámbitos que articula el dispositivo constitucional que propone (sociedad, política, instituciones, Constitución, etc.); así como conectar y establecer diálogos entre distintas disciplinas (derecho, ciencia política, filosofía). Para una perspectiva sobre el surgimiento de las ciencias sociales como relanzamiento de la filosofía política moderna, cf. B. Karsenti, De una filosofia a otra. Las ciencias sociales y la política de los modernos, San Martín, UNSAM Edita, 2017 y F. Callegaro, "Une réaction à la Réaction. Les sciences sociales et l’héritage révolutionnaire” en Conceptos Históricos, N6, 2019 pp. $190-214$.
} 
teoría del derecho y es un punto clave en la interpretación de su obra ${ }^{3}$. Sin embargo, en las reconstrucciones más recientes de su pensamiento este aspecto ha sido frecuentemente soslayado ${ }^{4}$. Considero que un adecuado esclarecimiento de esta cuestión permite iluminar aspectos relevantes para la comprensión de su obra.

En efecto, la episteme sociológica le permitió a Heller trazar una alternativa a lo que identificaba como una profunda crisis de la forma política moderna. En su diagnóstico, la emergencia de la democracia social había hecho implosionar el marco del Estado liberal de derecho y empujaba a trazar nuevos dispositivos constitucionales de organización social y política. Heller entendía la democracia social como una inédita situación histórica caracterizada por la progresiva consolidación de una sociedad propiamente política compuesta por una pluralidad de grupos con capacidad para establecer relaciones vinculantes entre sus miembros, así como para participar e incidir en la conducción del Estado ${ }^{5}$. Ante estas transformaciones estructurales, Heller estaba convencido de que el pensamiento jurídico de la época tenía la obligación de proyectar una forma política capaz de adaptarse a esta novel realidad ${ }^{6}$. Dentro este marco, la sociología se le ofrece como la episteme desde el cual es posible regenerar el saber jurídico y rearticular Estado, sociedad y derecho en torno a un dispositivo de gobierno capaz de asegurar la coordinación de este pluralismo social $^{7}$.

El énfasis en la dimensión sociológica fue parte importante de la recepción española de Heller. Para el caso, véase la influencia de Heller en la obra de autores como Enrique Gómez Arboleya, Nicolás Pérez Serrano, Manuel García Pelayo y en particular en el magisterio de Francisco Ayala. Para la recepción de Heller en España, al ya clásico estudio de Antonio López Pina "Hermann Heller y España" en H. Heller, Escritos políticos, Madrid, Alianza, 1984, habría que agregarle la minuciosa reconstrucción Sebastián Marín "Estudio introductorio" en El derecho político de la Segunda República, Madrid, Universidad Carlos III, 2011, en donde aporta datos interesantes sobre la influencia de Heller en el magisterio de Ayala, Llorens y Pérez Serrano. Por otro lado, es innegable que el reconocimiento y la valoración positiva de esta dimensión sociológica por parte de juristas e intelectuales vinculados al socialismo jurídico en España. Así Lucas Verdú identificaba en el trabajo de Heller un impulso central en la elaboración sociológica del concepto de Constitución (L. Verdú, "Socialismo y derecho constitucional" en Sistema N ${ }^{\circ} 17 / 18$, 1977). Es interesante advertir que tal como lo demuestra una figura como Renato Teves, el posterior desarrollo de la sociología jurídica haya encontrado en el trabajo de Kelsen y no en el Heller una de sus fuentes fundamentales. Sobre este punto volveremos más adelante en el trabajo.

4 Así, por ejemplo, en las exhaustivas reconstrucciones que ofrecen Peter C. Caldwell, Popular sovereignty and the crisis of German constitutional law: the theory \& practice of Weimar constitutionalism. Duke University Press, 1997 y David Dyzenhaus, Legality and Legitimacy: Carl Schmitt, Hans Kelsen, and Hermann Heller in Weimar, la perspectiva sociológica en la cual Heller filia su Teoría del Estado merece escasas menciones y un tratamiento superficial que no se corresponde a la centralidad que tiene en el desarrollo de sus premisas fundamentales.

H. Heller, “Estado de derecho o dictadura?” en Escritos politicos, op. cit.

6 Para esta cuestión: Sebastián Marín "Los fundamentos sociales, políticos y jurídicos del Soziale Rechtsstaat. Una relectura de Hermann Heller" en Res publica, 25, 2011, pp. 151-175. En particular la nota al pie $\mathrm{N}^{\circ} 27$ en donde ofrece un argumento que intenta mostrar el vínculo entre el pluralismo social y el énfasis puesto por Heller a las instancias de unidad tales como el propio Estado, pero también la nación.

En este sentido deben leerse las críticas de Heller a la teoría pluralista del Estado de Laski. Para Heller, la perspectiva seguida por Laski no había logrado afirmar la especificidad del Estado respecto a la
Nos interesa focalizar en dos funciones que la episteme sociológica desempeña en la construcción del dispositivo helleriano. En primer lugar, este abordaje le ofrece una perspectiva que, rompiendo con el supuesto individualista en torno a cuál se había edificado el Estado liberal de derecho, le permite mostrar las complejas relaciones de interdependencia que guardan entre sí los distintos grupos sociales. Este reconocimiento del carácter plural de sociedad lo conduce a asignarle al antagonismo un papel positivo para la producción jurídica de la solidaridad social. La necesidad de cooperación entre estos grupos sociales es el criterio que define la función del Estado, así como el que le da a la política su más noble objetivo. Dentro de este registro es que la democracia ocupa un lugar central en el pensamiento de Heller, en tanto habilita la constante mediación política de los antagonismos sociales. Como segundo aspecto y en estrecha relación con el primer punto, se advierte que la impronta sociológica del dispositivo constitucional que propone Heller hace emerger un régimen de temporalidad particular que se caracteriza por la constante renovación del contenido normativo en el que se apoya la organización política de la sociedad. La sociología jurídica se convierte así en el saber político central de un nuevo arte de gobierno, en tanto es capaz de hacer inteligibles los procesos de producción de orden jurídico, marcando el ritmo entre lo instituido y lo instituyente.

Para nuestra reflexión proponemos el siguiente recorrido. En primer lugar, revisaremos las discusiones que provocó la emergencia del Estado social (Sozialstaat), en Alemania. En particular respecto a cómo se planteó el vínculo entre ciencia del derecho y sociología. Esto es importante en tanto nos permitirá reconstruir el contexto de discusión en el que interviene Heller y desde el cual su abordaje sociológico representa una toma de postura. En un segundo momento mostraremos en qué medida la episteme sociológica le permite a Heller proyectar una alternativa capaz de resolver las aporías que la crisis de la forma política moderna había dejado al desnudo. En este sentido recuperaremos su análisis del fascismo, al cual va a descartar como una alternativa superadora. Por último, haremos explícito el régimen temporal a la que conduce el cáliz sociológico de su filosofía política.

\section{El Estado social y la disputa por la frontera entre derecho y sociología}

Hacia finales del siglo XIX, la consolidación en Alemania de un Estado con capacidad para intervenir en distintas facetas de la vida social tensionó la separación decimonónica entre Estado y sociedad civil. Este hecho tuvo como corolario una intensa discusión sobre las fronteras

pluralidad de asociaciones sociales. Para Heller resulta fundamental conciliar la realidad de la democracia social con un Estado con autonomía y capacidad para cumplir su función coordinadora. $\mathrm{Cf}$. $\mathrm{H}$. Heller, Teoría del Estado, México, Fondo de Cultura Económica. Para un panorama sintético sobre la cuestión del pluralismo social en las primeras décadas del siglo XX, cf. G. D. H Cole, La organización política. México, Fondo de Cultua Económica, pp. 57-65. 
disciplinares entre la ciencia del derecho (Jurisprudenz) y la sociología ${ }^{8}$. Es precisamente dentro de este marco que Heller optó por una reformulación sociológica de las relaciones entre Estado, sociedad y orden jurídico. Como veremos un poco más adelante, Heller intentó ofrecer una síntesis superadora de este debate, proponiendo un régimen de producción del derecho en el cual la sociedad, en tanto comunidad nacional democráticamente organizada, ocupa un lugar central.

Para principios del siglo XX la crisis del Estado de derecho liberal ya era plenamente advertida desde

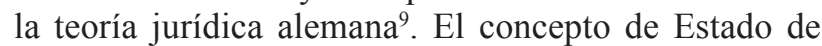
derecho había permitido delimitar el ámbito de intervención estatal, asegurando con ello un espacio de libre interferencia en la sociedad. Sin embargo, con los conflictos y desequilibrios inherentes a la sociedad de clases, tanto el derecho como el Estado se convirtieron en instrumentos centrales para la reorganización de la sociedad a partir de objetivos definidos desde el propio Estado. Esto implicó un cambio no sólo en la función del derecho sino también en la propia lógica de su aplicación. El carácter formal del Estado liberal de derecho implicaba que las normas sólo se activaran cuando una situación de hecho sucediera, imputando determinadas consecuencias a las acciones realizadas. Por el contrario, las nuevas funciones sociales que asumió el Estado dieron lugar a situaciones expresamente creadas mediante reglamentos, decretos y directrices administrativas que bajo plazos indefinidos iban dirigidos a grupos sociales específicos. Se trataba ya no de regular la actividad comercial espontánea de la sociedad, sino de crear o transformar relaciones sociales usando el derecho como un medio adecuado para este fin. Esta situación implicó que la sociedad policlasista, con sus diferencias y desigualdades, impregnara la lógica del derecho. De esta manera en torno a la producción jurídica se estableció una arena social y política en la cual: "segmentos de la sociedad negociaban tanto entre ellos como con los órganos del Estado que tienen la fuerza del derecho público"10. Estos cambios trastocaron los pilares sobre los cuales se había edificado el concepto liberal de Estado de derecho.

Este conjunto de transformaciones dio paso a una "querella sobre el método jurídico" que dominó la escena intelectual desde el final del imperio guillermino hasta la caída de la República de Weimar ${ }^{11}$. Uno de los tópicos en los que transcurrió este debate fue respecto a si las ciencias sociales -y en particular la sociologíatenían alguna utilidad para la toma de decisiones judiciales. El cambio en la lógica jurídica a la que condujo

8 Para una problematización historiográfica del Estado social, cf. P. Costa, "Lo Stato Sociale como problema storiografico" en Quaderni Fiorentini, $\mathrm{N}^{\circ}$ 46, 2007, pp. 41-102.

9 Cf. C. Galli, Genealogía de la política. Carl Schmitt y la crisis del pensamiento político moderno, Argentina, UNIPE, 2018, pp. 371554.

10 J.P. McCormick, "Max Weber and the Legal-Historical Ramifications of Social Democracy" en Canadian Journal of Law \& Jurisprudence, $N^{\circ} 17,2004$, pp. 143-184. La traducción es mía.

11 Cf. M. Stolleis, Public law in Germany, 1800-1914 en Berghahn Books, 2001 y O. Lepsius "Die Wiederentdeckung Weimars durch die bundesdeutsche Staatsrechtslehre", en Ch. Gusy (ed.), Weimars lange Schatten -"Weimar" als Argument nach 1945, Baden-Baden, Nomos, 2003, pp. 354-394. el Estado social llevó a que entraran en consideración un heterogéneo conjunto de relaciones y situaciones sociales sobre las cuales se buscaba incidir. Había, por lo tanto, razones suficientes para suponer que el método jurídico lógico-deductivo desarrollado en la dogmática del Estado liberal de derecho debía ser complementado por la sociología jurídica, entendida esta como una disciplina auxiliar en la decisión judicial. La cuestión dividió las aguas no sólo en la teoría jurídica sino también en la sociología, pues la polémica tensionaba inevitablemente la frontera y autonomía de estos dos saberes.

Durante la República de Weimar la filosofía neokantiana ofreció el lenguaje principal en el que se planteó buena parte de esta disputa entre fronteras disciplinares $^{12}$. Esto es importante en la medida en que la episteme sociológica a la que recurre Heller discute expresamente con esta perspectiva. En aquellos años de la República, la relevancia del neokantismo era doble. Por un lado, esta filosofía era en gran medida hegemónica en la teoría jurídica alemana. Pero también resultaba un punto de paso ineludible en la discusión política al interior del Partido Socialdemócrata Alemán, en donde había ganado una marcada relevancia ${ }^{13}$. En efecto, Kant se había convertido en el ariete de la crítica de los sectores revisionistas al lugar que ocupaba el marxismo en el socialismo. En el centro del debate estaba la cuestión respecto a si era posible derivar de los postulados de Marx una ética que complementara el abordaje científico que ofrecía el materialismo histórico. Para este heterogéneo sector, una de las repuestas posibles era emprender un "regreso a Kant" que permitiera depurar lo que quedaba de la "metafísica hegeliana" en los planteamientos de $\operatorname{Marx}^{14}$.

La distinción fundamental de la que parte todo planteamiento neokantiano es aquella que se da entre ser y deber ser (sein und sollen). Para la filosofía de Kant estos dos ámbitos constituían una dualidad insuperable. Bajo estos términos, los revisionistas argumentaban que, si bien el materialismo histórico ofrecía un tratamiento científico adecuado para develar el ser en el curso de la historia, una lectura socialista de Kant podía aportar un necesario deber ser que anclara al socialismo a una perspectiva ética que no era posible extraer del materialismo histórico. Como veremos más adelante, la postura política e intelectual que asumió Heller frente a esta dualidad ser/deber fue la de transformar el dilema filosófico en un problema sociológico. Apoyándose en Hans Freyer, quien sindicaba en Hegel una fuente central del desarro-

12 A. Carrino, "The Rebirth of Legal Philosophy within the Frame of Neo-Kantianism" en E. Pattaro y C. Roversi, A Treatise of Legal Philosophy and General Jurisprudence, Vol. 12, Netherlands, Springer, 2016, pp. 13-132.

13 Cf. H. Van der Linden, Kantian ethics and socialism, Hackett Publishing, 1988 y C. M. Herrera, "Kelsen y el socialismo reformista" en Revista de estudios políticos, $\mathrm{N}^{\circ} 96,1997 \mathrm{pp}$. 77-115.

14 En particular el "regreso a Kant" fue auspiciado por figuras como Eduard Berstein, Friedrich Lange, Karl Vörlander, Kurt Eisner y Hermann Cohen. Este último tal vez haya ofrecido el intento más ambicioso de articular una lectura socialista de Kant. La polémica también tuvo su resonancia fuera del neokantismo; desde el austromarxismo exponentes como Max Adler y Otto Bauer examinaron la relación entre Kant y Marx. Cf. P. Gay, The dilemma of democratic socialism: Eduard Bernstein's challenge to Marx, Collier Books, 1962 y H. Van der Linden, Kantian ethics and socialism, op cit. 
llo de la sociología alemana, Heller mostraba la "correlativa correlación" entre ambos reinos ${ }^{15}$. En efecto, para Heller ser y deber ser formaban una unidad dialéctica en la que ambos términos quedaban mutuamente implicados, dando lugar a procesos siempre contingentes e inestables en los cuales ambas dimensiones se retroalimentaban de forma constante. Si bien Heller compartía con los revisionistas la crítica al marxismo como doctrina partidaria no lo hacía así respecto a la dialéctica hegeliana, misma que en Teoría del Estado cumple el papel de principio dinamizador de esta dualidad ${ }^{16}$. En este sentido la alternativa sociológica emprendida por Heller debe ser vista como una toma de postura doble: frente al debate en torno a la teoría jurídica pero también respecto a las discusiones del socialismo alemán en la República de Weimar.

\section{El derecho entre el Estado y la sociedad}

Un buen punto de partida para establecer los contornos del debate es la polémica que despertó la posición de Hermann Kantorowicz expresada en Ciencia del derecho y sociología ${ }^{17}$. En dicho artículo planteaba la necesidad de incorporar a la sociología dentro de una teoría general del conocimiento jurídico. Partiendo de la distinción entre ser y deber ser, Kantorowicz proponía una perspectiva en la cual la dualidad kantiana daba lugar a un esquema trilateral de saberes. La dogmática jurídica (indagación sobre el sentido), la sociología (indagación sobre los hechos) y la filosofía del derecho (indagación sobre el valor) debían quedar articulados y mutuamente referidos con el objetivo de dar cuenta de la complejidad del hecho jurídico ${ }^{18}$. Para Kantorowicz el proceso de interpenetración entre el derecho y lo social hacía necesario que el abordaje jurídico pasara de ser una "ciencia de palabras" encargada de "la interpretación literal de las normas jurídicas" para convertirse en "una ciencia valorativa (Wertwissenchaft) al servicio de los fines de la vida social"19.

En un comentario a la posición de Kantorowicz, Max Weber mostró sus dudas respecto a este esquema propuesto. Siguiendo a Kant, Weber aludía a que ser y deber estaban referidos a diferentes tipos de validez

15 Cf. H. Freyer, La sociología, ciencia de la realidad, Buenos Aires, Losada, 1944. Para una lectura sobre el vínculo entre Hegel y el desarrollo de la sociología, cf. F. Callegaro, “_Hegel precursore della sociologia? forza e limiti di un'alternativa filosofica alle scienze social" en Etica \& Política, Vol. XVIII, 2016, pp. 243-273.

16 Esto no eximió a Heller de realizar una potente crítica a la concepción del Estado de Hegel. Esta diferenciación es fundamental en la construcción de su propia Teoría del Estado. Cf. A. Jiménez Colodrero, "La crítica de Hermann Heller a la teoría de la personalidad estatal de G.W. F. Hegel” en Cuadernos de filosofía, Nº 67-68, 2017.

17 H. Kantorowicz, "Rechtswissenschaft und Soziologie" In Verhandlungen des 1. Deutschen Soziologentagesvom 19. bis 22. Oktober 1910 in Frankfurt am Main, 1969, pp. 275-310.

18 H. Kantorowicz, La lucha por la Ciencia del Derecho, Buenos Aires, Olejnik, 2018.

19 Citado por R. Treves, "Sociología del Derecho y sociología de la idea de justicia en el pensamiento de Hans Kelsen", Cuadernos de la Facultad de Derecho, No 8, 1984, p. 103. Para una reconstrucción sobre cómo se fueron relacionando derecho y sociedad en la teoría jurídica, cf. N. Luhmann, "Sistema jurídico y dogmática jurídica" Centro de Estudios Constitucionales, 1983. que en realidad se relacionaban con dos concepciones del derecho radicalmente diferentes ${ }^{20}$. Para Weber la dogmática jurídica se distinguía por haber desarrollado el problema de la validez normativa bajo un enfoque lógico-deductivo. La justicia formal característica de la dogmática del Estado de derecho seguía estos parámetros. Por su parte, la sociología hacía referencia a una validez empírica de tipo casual que reparaba en la probabilidad de que una norma fuera efectivamente aplicada y a las consecuencias sociales que se derivaban de este hecho. Para Weber este segundo registro era más propio de la "justicia kadi" altamente discrecional y que dependía de la capacidad de una autoridad para imponer discrecionalmente diferentes criterios en la resolución de conflictos. Como ha señalado McCormick, muchos de los reparos que mostraba Weber respecto a una convergencia entre derecho y sociología tenían como trasfondo una valoración negativa sobre los efectos que el Estado Social pudiera tener sobre el canon racionalista del derecho moderno ${ }^{21}$. En su manuscrito inconcluso sobre sociología jurídica, Weber ahondaría en esta cuestión sugiriendo que la legalidad propia del Sozialstaat implicaba un retorno a la lógica patrimonialista premoderna $^{22}$. Para Weber, la función y lógica que había adquirido el derecho en el Estado social tenía como efecto una "desformalización" de las normas. Lo que el derecho ganaba en materialidad al tener como objetivo expreso el atender situaciones y grupos sociales concretos, lo perdía en abstracción y formalidad, dando lugar a una diversidad de criterios en su aplicación que ponían en riesgo el principio de igualdad ante la ley.

Esta polémica en torno a la dualidad kantiana entre ser y deber ser encontró diversas modulaciones. Tal vez el mayor grado de polarización lo podemos encontrar en el debate entre Hans Kelsen y Eugene Ehrlich. Sus posturas se enfocaron en resolver esta dualidad a favor de uno de los términos, estableciendo una identidad del derecho ya sea con el Estado (Kelsen) o con la sociedad (Ehrlich). En efecto, la propuesta de Ehrlich era descentrar el lugar que tenía el Estado en la teoría jurídica mostrando el papel que los grupos sociales tenían en la creación de normas. En sus Principios de sociología jurídica, Ehrlich afirmaba que la principal función del derecho era la creación de orden a través de la sociedad y al interior de los distintos grupos que la componen ${ }^{23}$. Para Ehrlich, muchas de estas normas no eran producidas por el Estado, sino que emergían de la propia actividad de los grupos sociales. Ehrlich se refirió a estas normas como los "hechos de la ley" que no eran sino relaciones sociales que funcionaban en la práctica como relaciones

20 M. Weber, "On Legal Theory and Sociology" [1911] en A. Jacobson y B. Schlink, "Weimar. A Jurisprudence of Crisis", University of California Press, 2000.

J. P. McCormick, op. cit.

Publicado en M. Weber, Economía y sociedad, México, FCE, 2008. E. Ehrlich, Fundamental principles of the sociology of law, New York, Routledge, [1916] 2000. En este sentido Ehrlich propone una tipología que busca clasificar las normas tal como aparecen en distintas fuentes: a) el derecho público del Estado y su legislación; b) el derecho tal como aparece en la doctrina y en las decisiones judiciales; y finalmente c) los hechos de la ley en donde el derecho aparece inscrito en las relaciones sociales. 
jurídicas, siendo así "una fuente de orden social"24. Bajo este esquema, la sociología jurídica por la que apostaba Ehrlich no funcionaba sólo como una subdisciplina dentro del campo de la teoría jurídica, sino que se trataba de una meta-teoría sobre la producción social del derecho. En este sentido Ehrlich afirmaba que desde "el momento que el derecho es un fenómeno social toda clase de ciencia jurídica es una ciencia social (...) la ciencia del derecho, en el estricto sentido del término, es una parte de la ciencia teórica de la sociedad, o lo que es lo mismo, una parte de la sociología"25.

La devastadora crítica que Kelsen (1915) realizó a la concepción de Ehrlich señalaba que la propuesta de su colega conducía inevitablemente a conclusiones falsas. Al establecer una sinonimia entre normas jurídicas y hechos sociales, Ehrlich había colapsado fatalmente la dualidad kantiana impidiéndole con ello presentar un criterio claro que permitiera distinguir el ser del deber ser. Con ello el modelo propuesto perdía un criterio claro que permitiera identificar la especificidad del derecho en tanto orden normativo. Para Kelsen, la postura de Ehrlich diluía el carácter normativo del derecho en lo socialmente existente. La especificidad normativa del derecho quedaba así oculta en una tautología en la cual lo legal coincidía con lo socialmente existente. Siguiendo en este punto a Weber, para Kelsen todo intento de articular ser y deber ser ponía en crisis el abordaje científico del derecho. Más aún: si Weber todavía admitía la existencia de dos tipos de validez del derecho (formal y empírica), para Kelsen el problema de la validez sólo podía ser abordado mediante una ciencia del sentido de carácter estrictamente formal. La sociología y sus explicaciones causales resultaban totalmente ajenos al método jurídico. De ahí que, algunos años más tarde, Kelsen asumiera en su Teoría pura del derecho el objetivo expreso "rescatar" a la teoría jurídica de todo intento de contaminación sociológica, afirmando una tajante separación entre ambos saberes ${ }^{26}$. Desde su perspectiva, las tentativas de vincular la ciencia del derecho con la sociología no podían ser otra cosa que una coartada para introducir el debate ideológico al interior de las premisas del Estado de derecho. Sólo una separación entre ambas podía impedir que las plurales concepciones de la vida justa presentes en la sociedad y sus grupos inundaran la lógica del derecho, transformando con ello lo jurídico en un arma de lucha partisana.

Desde la óptica de Kelsen, posturas como las de Kantorowicz y Ehrlich eran del todo inadecuadas pues carecían de un criterio claro por el cual diferenciar los comportamientos jurídicos de los no jurídicos. Para la teoría pura del derecho, el carácter normativo del dere-

24 B. Van Klink, "Facts and Norms: The Unfinished Debate between Eugen Ehrlich and Hans Kelsen" in M. Hertogh (ed.), Living Law: Reconsidering Eugen Ehrlich, Oxford, Hart Publishing, 2009, pp. $127-156$.

25 R. Treves, "Sociología del Derecho...", op cit, p. 103.

26 Para Kelsen todo intento de vincular internamente sociología y derecho resultaba sospechoso de encubrir un disimulado regreso a las premisas del derecho natural. Desde su perspectiva, el lugar que antes habían ocupado las leyes de la naturaleza en la justificación del derecho, en el positivismo sociológico lo pasaban a ocupar la identificación de determinaciones sociales. H. Kelsen, Teoría pura del derecho, Buenos Aires, Eudeba, 1999. cho estaba dado exclusivamente por su capacidad para establecer la diferencia entre lo legal y lo ilegal, administrando por la vía del derecho los medios coactivos del Estado. Todo acto jurídico era también y al mismo tiempo un acto estatal ${ }^{27}$. Se trata una concepción del derecho que lo postulaba como un sistema semiótico herméticamente cerrado sobre sí mismo. La plena coherencia interna y el carácter integral del edificio jurídico era un postulado central de esta concepción. Por lo tanto, la ciencia jurídica debía operar exclusivamente mediante un abordaje deductivo orientado a indagar el sentido interno presente en el orden normativo con total independencia de las consideraciones sobre la sociedad y sus tensiones. Con ello Kelsen intentaba poner a resguardo las conquistas logradas por el Estado de derecho ante el posible desborde sociológico provocado por la emergencia del Estado social ${ }^{28}$.

En explícito descuerdo con la posición de Kelsen, en el esquema que propone Heller en su Teoría del Estado la frontera entre sociología y derecho aparece delineada bajo una conexión interna que lo sitúa en las antípodas del primero. Sin embargo, es necesario advertir que, tal como lo evidencian algunos de los pasajes más importantes de Teoría del Estado, es innegable que Heller valoró positivamente y sopesó con cuidado algunos aspectos esenciales de los reparos que ponía la crítica kelseniana a disolver la normatividad del derecho en lo socialmente existente ${ }^{29}$. En contraste con la propuesta de Ehrlich, Heller le asignaba un rol de mediación central al derecho positivo emitido desde el Estado y se preocupó por ofrecer un esquema que, sin confundir ser con deber ser, permitiera dar cuenta del carácter productivo de las tensiones que surgen entre la sociedad, sus grupos y el orden jurídico resguardado por el Estado. En este sentido sería erróneo ver en la propuesta de Heller una simple reacción antipositivista equiparable a la propuesta de $\mathrm{Schmitt}^{30}$. Por el contrario, la posibilidad de conciliar un sentido de justicia socialmente construido con la importancia técnica que Heller le adjudicaba al derecho positivo lo condujeron ensayar una robusta justificación de la democracia en tanto régimen de producción del derecho.

Dentro del debate propiciado por la emergencia del Estado Social, el diagrama helleriano se propuso conectar sociedad y derecho buscando que ninguno de los términos quede subsumido o reducido en el otro, identi-

27 Cf. L. Vinx, Pure Theory of Law: Legitimacy and Legality, Oxford University Press, 2007.

28 Paradójicamente, para Renato Treves, op cit. el hecho de que Kelsen se mostrara intransigente respecto a establecer cualquier tipo de vínculo entre ser y deber ser, habría tenido un efecto positivo en el posterior desarrollo de la sociología jurídica pues permitió delimitar con mayor precisión su propio objeto de la sociología jurídica y ofrecer una sólida base argumental sobre la cual sostener la autonomía de la disciplina respecto a la ciencia del derecho.

29 D. Dyzenhaus, "Introduction to Hermann Heller" en A. Jacobson y B. Schlink, op. cit.

30 La identificación de Heller con el anti-positivismo es un lugar recurrente en la bibliografía y a mi parecer desmerece la complejidad de los planteamientos que se encuentran en Teoría del Estado. Si bien es innegable la crítica al formalismo positivista tal como hemos descrito en el primer apartado, Heller no aboga por una superación del derecho positivo sino por su reforma democrática. Sin tener en cuenta este importante matiz, algunos pasajes centrales de Teoría del Estado resultan inexplicables. 
ficando aquellos puntos nodales en los que estos ámbitos se conectan internamente. En su propuesta, las tensiones provocadas por la creciente intervención del Estado se disipaban mediante un proceso de democratización que ponía el foco en el carácter propiamente político y social de la acción estatal. El problema de la discrecionalidad se resolvía dándole un cauce institucional apropiado a la dimensión política de la sociedad. En la búsqueda de este equilibrio, la episteme sociológica adquiere una función central. Si bien el objetivo principal de Teoría del Estado no era el de ofrecer una teoría jurídica como tal, en ella encontramos diversos elementos que nos informan sobre la concepción del derecho que la anima y que resulta central para la propia definición del Estado y la función social que su autor le adjudica.

Son dos los aspectos que Heller va a intentar resolver en su teoría del Estado y que se vinculan con el debate que hasta aquí hemos reconstruido. En primer lugar: la construcción de un dispositivo constitucional en el cual la relación entre decisión estatal y norma jurídica se vinculan mediante una concepción sociológica de la legitimidad. En efecto, la constante producción social y democrática del orden jurídico es la condición que permite trazar una recomposición de la relación entre Estado y sociedad más allá de estrecho marco liberal del Estado de derecho. En segundo lugar: el bosquejo de una sociología jurídica como una nueva arte de gobierno, en tanto es capaz de clarificar los pasajes mutuos entre la normalidad social (lo que en un momento determinado existe en la sociedad) y la normatividad del derecho (un deber ser en torno al cual se sintetiza en el problema de la validez social de las normas). Ambas cuestiones resultan centrales para la fundamentación del régimen democrático de producción del derecho por el que aboga Heller. El reconocimiento social del orden normativo resulta esencial para asegurar la función coordinadora que el Estado tiene frente a la pluralidad social.

\section{La crisis de la forma política moderna y la alternativa sociológica}

La teoría del Estado de Hermann Heller fue publicada póstumamente en 1934, luego de su repentino fallecimiento un año antes. Esta obra fue concebida explícitamente como una respuesta sistemática a lo que su autor identificaba como una profunda crisis de la forma política moderna. Crisis que en Alemania tenía como trágico capítulo el ascenso del nacionalsocialismo. Para comprender en qué medida la teoría del Estado helleriana intenta responder a los desafíos de su contemporaneidad resulta conveniente volver su ilustre análisis sobre el fascismo ${ }^{31}$.

En Europa y el facismo (1929), Heller ubica al pensamiento jurídico-político fascista en su justa dimensión. Es decir, como una falsa y peligrosa respuesta a la crisis a la que había conducido el positivismo formalista de la segunda mitad del siglo XIX ${ }^{32}$. Sin embargo, el profun-

31 H. Heller, "Europa y el fascismo" en Escritos politicos, Madrid, Alianza, 1985.

32 Como desarrollaremos más adelante, para Heller este formalismo jurídico se expresaba en la teoría del Estado propia de la dogmática do rechazo que le despertaba la alternativa proyectada por el fascismo -y que para Heller estaba representada en Alemania por la doctrina de Carl Schmitt- no le impidió reconocer que detrás de su emergencia se encontraba un problema estructural al que había que responder adecuadamente. El abordaje sociológico que Heller sigue en Teoría del Estado le ofrece una perspectiva capaz de generar un conocimiento adecuado para resolver el problema central de dicha crisis y que el fascismo, a pesar de su alta autoestima, había dejado intacto. Nuestro objetivo en este apartado es entonces reconstruir el diagnóstico general que lleva a Heller a buscar en la episteme sociológica un camino capaz de superar las aporías del liberalismo.

Las primeras líneas de Europa y el fascismo plantean el problema de manera rotunda: "el Estado europeo arrastra en la actualidad una crisis difícil y peligrosa; su forma y contenido necesitan renovarse con urgencia". La incógnita a la cual buscará dar solución a lo largo de su ensayo es si efectivamente el fascismo puede ser considerado legítimamente como una renovación de este tipo. La respuesta, por supuesto, es por la negativa ${ }^{33}$. Sin embargo, la frase de apertura que hemos citado nos pone cara a cara con un aspecto central del pensamiento de Heller y que remite a las categorías de mayor grado de abstracción sobre las que se apoya su diagnóstico: la relación entre forma y contenido. En efecto, para Heller: "los defectos de la forma política no hacen más que reflejar los defectos del contenido".

Desde la perspectiva helleriana el formalismo jurídico liberal había favorecido las condiciones para que se efectuara una profunda desconexión entre forma y contenido. La crítica de Heller señalaba que la cesura entre ambas cuestiones había desechado cualquier intento de pensar la conexión entre un orden justo y la expresión formal de dicho orden. Este es un problema cardinal en la medida en que para Heller: "más allá del bien y del mal no existe el derecho ni el Estado. Sólo en virtud de ideales jurídicos concretos se legitima e integra esencialmente el Estado (...) No hay comunidad política de aspiraciones, ni comunidad jurídica, sin una base común de valores políticos"34. Para nuestro autor, la teoría formalista del Estado que había dominado la dogmática jurídica fomentó y exacerbó las condiciones de la actual crisis al marginar hacia lo impensable cualquier tipo de relación interna entre el contenido axiológico sobre el cual toda organización social de hecho descansa (sus principios jurídicos) y la forma política que permite expresar ese contenido (su traducción constitucional en un orden material).

Para Heller el problema con el fascismo era que, si bien este movimiento se presentaba como una renovación de la forma política, su intervención no era más que la radicalización de las aporías propias del liberalismo. En efecto, al reducir el problema del contenido normativo a la posesión del aparato coactivo del Estado

jurídica tal como fue desarrollada en Alemania en el marco del Estado liberal de derecho. Sobre este tema: cf. R. Cavallo, "La critica al formalismo giuridico nel pensiero di Hermann Heller", en Quaderni Fiorentini, $\mathrm{N}^{\circ} 39,2010$, pp. 405-435.

33 Para este tema, cf. J.L. Monereo Pérez, "Fascismo y crisis política de Europa: crítica del Fascismo en Hermann Heller" en ReDCE, $n^{\circ} 7$, 2007, pp. 379-420.

34 H. Heller, "Europa y el fascismo", op. cit., p. 30. 
y su capacidad para imponer su voluntad por la fuerza, no sólo no se habían movido un ápice de los problemas por el formalismo, sino que, al fundamentar esto en una subordinación del derecho a la violencia había liquidado cualquier apariencia de justicia, sumergiendo al derecho en el más profundo irracionalismo. Ante la "norma sin contenidos" del positivismo formalista, el fascismo afirmó "la actividad sin normas" 35 . En ambos casos y por vías diferentes, el problema del contenido justo del derecho había quedado sin ser abordado: "Por esta razón todos los conceptos normativos y todos los imperativos del fascismo (...) son tan vacíos de contenido, por lo menos como los conceptos paralelos del racionalismo burgués del Estado de Derecho"36. El fascismo era una reacción a la abstracción propia del liberalismo que sin embargo reproduce y agrava la crisis pues muestra hasta el absurdo las consecuencias de la incapacidad para establecer una forma política en la cual el orden jurídico estuviera fundado en una idea sustancial de justicia. Para Heller la violencia y la fuerza no pueden nunca ofrecer un fundamento real para la organización social.

Si bien para Heller la dimensión epistemológica (separación entre forma y contenido) de la crisis tiene una importancia central, de ninguna manera su diagnóstico se reducía a este factor explicativo. De ser así, su postura se acotaría a las premisas de un idealismo que poco tiene que ver con la naturaleza social e histórica que nuestro autor le asigna a la reflexión sobre el Estado. En efecto, para Heller la crisis era consecuencia de cambios sociales, políticos y culturales muy concretos que habían desembocado en el desencuentro entre la estructura social imperante y la propia forma del Estado ${ }^{37}$. Dentro esta problemática, la desconexión entre contenido y forma adquiere el tono de un desenlace dramático. En la situación histórica contemporánea, dicha separación se había convertido en el obstáculo que dificultaba todo intento de renovación y de adecuación de la forma política: "Parece como si nuestra época no acertara a dar una configuración política satisfactoria a la democracia social de masas", reflexionaba nuestro autor, en un tono un tanto afligido. Veamos entonces cómo se vinculan la dimensión epistemológica con la histórico-social en el diagnóstico helleriano.

Heller identificaba la situación social vigente con el término "democracia social de masas". Esta se caracteriza por un alto grado de complejidad producto de la politización de las desigualdades económicas, el consecuente surgimiento de diferentes organizaciones de clase, así como por las relaciones de interdependencia que los diferentes grupos sociales mantienen entre sí. De esta manera, la democracia social indica el arribo definitivo de una sociedad política estructuralmente pluralista y que tensionaba decididamente el estrecho marco liberal del Estado de derecho. Es dentro de este status histórico que el Estado adquiere una particular función, que no puede ser otra cosa que función social. En tanto este pluralismo social no tiene un orden natural previamente dado, el

35 En teoría del Estado estas dos posiciones serán asociadas a dos nombres propios: Kelsen y Schmitt.

36 H. Heller, "Europa y el fascismo", op. cit., p. 69.

37 Como veremos, para nuestro autor el Estado no puede ser concebido como un espíritu objetivo o una simple idea, este es un objeto de la cultura y como tal es siempre un fragmento de la historia.
Estado -como formación y estructura histórica- se presenta como un recurso objetivo capaz de colaborar con la organización de esta complejidad. Esta función implica que el Estado debe actuar la cooperación social; lo que fundamentalmente implica favorecer la coordinación de las "oposiciones de voluntades" que conforman lo social. En otras palabras, la función social del Estado se desprende del reconocimiento de la sociedad como un espacio político de naturaleza conflictiva en donde conviven una pluralidad de grupos con perspectivas antagónicas que hay que coordinar, sin que esto signifique subordinarlos por la fuerza. El problema que se instala es que, para poder cumplir con esta función social, el Estado necesita ser capaz de hacer inteligible los principios jurídico-políticos que sirven de orientación normativa a su acción. Dicho de otro modo, tiene que clarificar los criterios políticos a partir de los cuales el Estado va a actuar la cooperación social. El reconocimiento social de estos principios se vuelve el dato central de la política y de la acción de gobierno.

Ante esta problemática Heller le asigna un papel político central a la adecuada dilucidación de la "comunidad de valores y aspiraciones", misma que funciona como condición de sociabilidad de la formación social. En un contexto de crecientes desigualdades y antagonismos de clase, para Heller la obligación política sólo adquiere sentido si el Estado logra articular los principios jurídicos fundamentales que sirven de sustrato común a la comunidad política. Es indispensable que la organización de la cooperación social se encuentre socialmente legitimada. Para Heller la relación entre el Estado y el pluralismo social se da siempre en el marco de una "comunidad nacional de cultura" ${ }^{38}$. La democratización de la nación se convierte así en una condición necesaria para que el Estado pueda cumplir de manera adecuada su función como medio de articulación de la cooperación social $^{39}$. Sin esa referencia a lo común-nacional "pierde toda su fuerza el principio constitutivo de la organización de la democracia". Sin una adecuada dilucidación de este entramado común, la obligación política -entendida como la relación mediada jurídicamente entre los grupos sociales y el Estado-, carece de sustento.

Ahora bien, en coherencia con el abordaje sociológico que perfeccionará en Teoría del Estado, este sustrato común no debe ser considerado ni como una esencia ni como una identidad trans-histórica o esencia. Por el contrario, se trata siempre de un "momento entre lo devenido y lo que devendrá". Para Heller, el contenido de lo común-nacional se construye siempre en forma dialéctica entre un ser (una existencia actual) y un deber ser que condiciona su orientación hacia el futuro. En tanto

38 En Socialismo y nación Heller lo define de esta manera: "La nación es para nosotros una comunidad de pautas de conducta y de convicciones axiológicas, una comunidad de cultura”. Es evidente la influencia de Otto Bauer en esta definición.

39 Esta afirmación conduce a dos tópicos sobre los cuales Heller insistirá en toda su obra: a) la importancia de que el Estado asegure y produzca cierta homogeneidad, lo cual lleva a una justificación de los derechos sociales; y b) la reivindicación de la clase obrera como participe de la cultura nacional, misma que se ve engrosada, enriquecida y transformada con su ingreso. Cf. "Democracia y homogeneidad social”, así como y Socialismo y nación, ambos en Heller, H., Escritos politicos, op. cit. 
el pueblo es interpretado como una entidad sociológica, para el Estado esa comunidad de valores nunca es definible a priori (por fuera de su cauce social) ni para siempre (fuera de su cauce histórico). Es dentro de esta dinámica que Heller ofrece una justificación de la democracia que resulta clave a la hora de posicionar su alternativa en expresa oposición con aquella promovida por el fascismo.

\section{La producción social y democrática del derecho}

El abordaje sociológico le permite a Heller identificar la función objetiva que debe cumplir el Estado frente a la nueva democracia social. Producto de la reflexión y el análisis de las condiciones que le impone la propia composición social, el Estado obtiene una determinada función: organizar la cooperación de las partes de una sociedad intrínsecamente plural (policlasista) y conflictiva ${ }^{40}$. Esta situación hace indispensable que el Estado cuente con un orden normativo legitimado por la propia sociedad. En la interacción entre ambas premisas es donde en donde el vínculo entre democracia política y democracia social aparece como solución al problema de la relación entre forma y contenido.

En efecto, la democracia política (es decir, las instituciones de la democracia representativa) es presentada por Heller como el mecanismo (o técnica) de reducción de la complejidad social que mejor se adapta a la necesidad de hacer inteligible ese orden común de valores. En otras palabras, la virtud del orden democrático radicaría en que ahí la relación entre forma y contenido se establece bajo una conexión interna que permite que su vínculo se actualice constantemente. De esta manera la dilucidación de lo común se vuelve parte constitutiva de la forma política democrática (política y social a la vez). La relación irreductible entre la formación democrática de la voluntad unitaria del Estado y el carácter plural de la sociedad se convierte entonces en el dato central de la política. Una vez formada esta voluntad del Estado, la sociedad no queda absorbida en su representación estatal, sino que mantiene un estatuto político propio que permite que los grupos sociales se reposicionen frente a la acción de gobierno. Este juego de relativas autonomías es el dato estructural que le permite a la democracia mantener constante la actualización entre forma y contenido.

La democracia política no agota a la democracia social. Es bajo esta premisa que en el dispositivo helleriano la relación dialéctica entre ambas le permite al Estado asegurarse las condiciones para cumplir con su función social. La necesidad de esclarecimiento de lo común por la vía democrática permite reconducir los antagonismos bajo una forma diferente a la de la enemistad absoluta promovida por la filosofía schmittiana. La mutua pertenencia de las partes a una misma comunidad nacional pone el acento en un trabajo propiamente político capaz de transformar el conflicto en decisiones democráticas. Es este sentido que la dialéctica entre democracia polí-

40 En este sentido cobra relevancia la crítica de Heller al marxismo, en particular a la idea de "lucha de clases sociales", no en el sentido de una negación del antagonismo, sino de que sitúa a este en el paradigma de la "guerra civil". tica y democracia social se vuelve un dispositivo agonal en la Teoría del Estado de Heller.

Dentro de este marco la posibilidad de conectar forma y contenido se le presenta a Heller como uno de los aspectos más urgentes si se quiere llegar a una reformulación de la teoría del Estado capaz de responder a la crisis ya señalada. En efecto, si la posibilidad de descubrimiento/producción de esta comunidad de valores y aspiraciones no es parte constitutiva e integral de la forma política, el Estado no tendrá más remedio que seguir operando en el vacío normativo, en el monólogo absoluto de su racionalidad interior y de la forma pura de su legalidad. De ahí que expresiones como "la ley es la ley" o "todo Estado es Estado de derecho" le parezcan a Heller producto de una sordera epistémica que no puede sino azuzar las brasas de la crisis. Si se parte del supuesto de que toda ley es válida en cuanto tal sólo en la medida en que esta haya sido emitida por el Estado, es decir, en tanto tenga una forma-de-ley, se pierde de vista que la validez del orden jurídico es en última instancia social y política. Para Heller, esta validez sólo puede descubrirse y ponerse a prueba a través de una mediación democrática de los antagonismos sociales.

En el dispositivo helleriano la legitimidad democrática es el resultado de un proceso constante y contingente de dilucidación de lo común y es postulada como un momento interno de la validez de la ley. En la forma democrática el principio de soberanía popular y la dinámica representativa se instituye como un espacio de interacción política en el cual los principios jurídicos que orientan la función del Estado se ven constantemente puestos a prueba, incluyendo la posibilidad de su rechazo, conservación o transformación por parte de la sociedad y sus grupos. En este sentido, David Dyzenhaus ha caracterizado acertadamente a la filosofía jurídico-política de Heller como un intento de "democratización de la razón" Sin embargo, Dyzenhaus relaciona esta perspectiva con el papel que tenía el derecho natural en Hobbes, ya que el Estado quedaría sujeto a ciertos principios que trascienden al derecho positivo-estatal. Sin embargo, el abordaje sociológico seguido por Heller lo conduce a consecuencias muy diferentes y que Dyzenhaus parece por momentos subestimar. Tal como lo ha puesto de relieve la interpretación dada por Schmitt, en el esquema hobbesiano la existencia de poderes indirectos al interior del cuerpo político sólo pueden ser interpretados como una amenaza a la soberanía y el germen de la guerra civil. Sin embargo, para Heller, estos poderes ahora denominados sociales son la condición necesaria para poner en marcha la dinámica que produce estos principios jurídicos. De ahí que, en contraste con el derecho natural, estos principios políticos son siempre y en todo momento una incógnita a la cual sólo cabe aproximarse poniendo en el centro de la escena una política democrática que difícilmente puede encontrar lugar en el esquema hobbesiano y que nada tiene que ver con el derecho natural.

Lo realmente innovador del planteo de Heller es que al conectar internamente forma y contenido por la vía

\footnotetext{
41 D. Dyzenhaus, "Kelsen, Heller and Schmitt: paradigms of sovereignty thought" en Theoretical Inquiries in Law, 16(2), 2015, pp. 337-366.
} 
de una justificación de la democracia, termina por trastocar una de las aporías fundacionales del racionalismo ilustrado y es aquella que identifica la unidad del Estado con la unidad del pueblo ${ }^{42}$. En la perspectiva helleriana la decisión vinculante y unitaria del Estado no supone una reificación de la unidad del pueblo ya que éste permanece como una realidad concreta, de carácter plural y conflictivo con una lógica política propia que se mantiene vigente aún frente a la capacidad del Estado de actuar unitariamente. Al considerar al sujeto de la soberanía como una realidad sociológica (es decir como una sociedad de clases), el pueblo deja ser un principio político formal y abstracto para convertirse en una entidad política con capacidad de actuar frente al Estado. De ahí que Heller en explícita contradicción con el modelo hobbesiano considere al pueblo como una entidad preexistente al Estado, es decir como una "nación política" que tiene para si una consistencia y una dinámica más allá del fenómeno estatal. El carácter plural y antagonista de la sociedad no se resuelve en la unidad de actuación del Estado. Por el contrario, la tensión entre ambos polos de la relación se mantiene siempre como un aspecto regulatorio de la acción del Estado por la vía de la construcción social de la legitimidad. El Estado no es la unidad del pueblo, sino una unidad de acción en el pueblo.

En la medida en que el Estado queda inscrito en un proceso social de discusión sobre los principios que deben orientar su función, el Estado legítimo deviene entonces Estado sociológico. Es decir, se revela como una formación y una estructura objetiva condenada a buscar en la realidad social los principios jurídicos que deben servir como orientación normativa en el ejercicio de su función objetiva: la de servir como instrumento de organización social. El Estado se revela como una estructura interna de la sociedad que, manteniendo una autonomía relativa frente a la pluralidad de grupos sociales que la conforman, se presenta como un medio efectivo para organizarla. Como precisaremos enseguida la reformulación sociológica del Estado que ensaya Heller tiene como consecuencia la temporalización de la relación entre forma y contenido. Es decir, su emplazamiento dentro de un proceso dialéctico entre lo actualmente existente y las posibilidades de su transformación. Situación ante la cual la sociología jurídica se presenta como un saber fundamental dentro de un arte de gobierno capaz de responder a la dinámica democrática.

\section{La sociología jurídica como nueva razón de Estado}

Precisaremos ahora cuáles son las características básicas de la sociología que sigue Heller para reformular la relación entre Estado, derecho y sociedad. Como hemos

42 Esta aporía queda expuesta en su análisis del fascismo cuando Heller señala los ecos rousseaneanos que vibran en la pluma de Gentile, para quien sólo es libre "aquel que sienta el interés general como el suyo propio y marche de acuerdo con la voluntad general. Libre será, por tanto, el italiano que sienta quiera y obre como Mussolini (...) Sus propias ideas de inmanencia le obligan a buscar una justificación democrática y liberal de su dominación absolutista" (H. Heller, "Europa y el fascismo", op. cit., pp. 58-59). adelantado, Heller tensiona la distinción ser/deber ser relacionando internamente ambos términos mediante una particular interpretación de la dialéctica hegeliana. Refutando la interpretación neokantiana que ve en la distinción ser/deber ser dos reinos incomunicables, Heller opta por un esquema en el que ambas dimensiones entran en tensión y conflicto productivo. Para la dialéctica que construye Heller, el resultado de la relación entre estos elementos no produce una síntesis superadora si no que tan sólo logra un particular status, contingente e inestable que se vuelve a procesar dialécticamente. Esto es clave para entender cómo la episteme sociológica le permite a Heller inscribir al Estado en un régimen temporal particular que se articula en torno al vínculo no armónico entre derecho positivo y pluralismo social. Dentro de este marco, la sociología jurídica emerge como un saber político central en la medida que es capaz de hacer inteligible la dinámica que tiene lugar en este espacio de tensiones productivas.

Para Heller "el hombre es esencialmente utópico" en la medida en que "es capaz de contraponer al ser un deber ser y valorar el poder actual según una idea del derecho" "43. Desde esta particular antropología se propone explicar al Estado no ya en los términos de Hegel en tanto realización absoluta del principio ético, sino como una organización social cuya justificación depende en última instancia del contenido que es capaz de expresar. En efecto, la concepción del Estado que atraviesa su obra refleja la tensión dialéctica entre ser/deber ser. En tanto ser, el Estado se define como una formación social que resulta efectiva para sostener la existencia humana: es una prótesis antropológica. Sin embargo, para cumplir esta función es indispensable que esta formación descanse en principios y criterios que satisfagan el carácter utópico que anima a los hombres. El hombre, como cualquier otro animal, necesita hacerse de un refugio; sin embargo, en tanto es un ser cultural siente inevitablemente la compulsión de hacer del refugio un verdadero hogar. Esta es la antropología que sirve como base a la sociología helleriana.

La constante transformación del orden jurídico producto de su irresoluble tensión con el pluralismo social funciona como el principio dinamizador que le permite al Estado asegurarse una justificación ética que, sin embargo, nunca llega a ser plena. En este sentido, para Heller el "derecho es la forma de manifestación necesaria, tanto desde el punto de vista moral-espiritual como técnico, de todo poder permanente. La función creadora del poder que el derecho tiene se haya condicionada, de un lado por su normatividad y, de otro, por su positividad"44. Vemos entonces que, en contraste con la concepción jurídica de Kelsen, para Heller el carácter positivo-coactivo del derecho es sólo una de las dos dimensiones que define al derecho como fenómeno social. La segunda de ellas y en la que Heller finca el peso del carácter normativo, refiere al reconocimiento social que valida o no el contenido concreto que expresa el orden jurídico. Es en esta segunda dimensión en donde hay

\footnotetext{
3 H. Heller, Teoría del Estado, op. cit., p. 282

44 Ibidem, p. 247.
} 
que buscar la fuerza vinculante de las normas ${ }^{45}$. De tal manera que, como afirma Heller: "al hablar aquí de derechos nos referimos, en primer término, a los principios morales del derecho que constituyen la base de las normas jurídicas positivas. Es inmanente a todos estos principios, cuya validez ideal ha de ser supuesto, la exigencia de una validez social" ${ }^{16}$. Notemos aquí que mientras la validez ideal de estos principios actúa como un supuesto inalcanzable, el reconocimiento social de ellos se presenta como una exigencia y, por lo tanto, es situada al nivel de lo concreto y lo actual ${ }^{47}$.

En oposición a la dogmática jurídica tal como se desarrolló en el Estado liberal de derecho, para Heller el Estado debe ser considerado como una formación histórica que pertenece al mundo de la cultura. Para Heller los objetos de la cultura "se muestran como procesos vivos", como "formas históricas de la actividad humana"48. Reformulando la frase de Renan, para Heller el Estado es un plebiscito de todos los días y no la expresión inmanente del espíritu absoluto de una nación. $\mathrm{Su}$ existencia depende enteramente de que su unidad se realice constante y cotidianamente por medio de acciones concretas. Mientras que las ciencias del sentido presentan al Estado como una magnitud ideal, para el abordaje sociológico del Estado éste sólo puede ser considerado como una estructura con capacidad para actuar en el devenir de la historia. De tal manera que una tarea esencial de la Teoría del Estado es especificar y delimitar los medios por los cuales esta estructura puede actuar unitariamente y mostrar cómo el Estado puede gestionar su propia historicidad mediante ellos.

Esta cuestión nos pone cara a cara con el último aspecto que nos interesa destacar de la reformulación sociológica del Estado emprendida por Heller: su relación con lo histórico-social. El gran problema que se le plantea a la Teoría del Estado es el de explicar el hecho de que un objeto de la cultura pueda asumir y procesar su propia condición histórica. Si bien para Heller la historicidad es un dato fundamental del Estado, esto no significa que la teoría del Estado sea parte la ciencia de la historia. Su objeto, por el contrario, cae dentro del ámbito de una ciencia de estructuras; es decir, aquella que se encarga de poner de manifiesto los aspectos que dotan a la formación social llamada Estado de los medios para navegar por el torrente de la historia y su incesante dinámica de cambio. Se trata, por lo tanto, de "concebir el Estado como una estructura en el devenir". Para Heller el Estado como estructura se caracteriza por

45 Si para Heller la gestión legal de los medios coactivos del Estado tiene una importancia técnica, su carácter normativo no encuentra su explicación ahí.

46 H. Heller, Teoría del Estado, op. cit., p. 248.

47 La idea de "principios jurídicos" es un punto esencial en el dispositivo helleriano y al mismo tiempo de uno de sus aspectos más ambiguos. En efecto, se trata de la categoría que permite conectar ubicar a la sociedad al interior del régimen de producción democrático. Sin embargo, es un aspecto que hubiera merecido más atención por parte de Heller. Considero que resaltar la especificidad de la alternativa sociológica en la que se sitúa Heller puede ayudar a precisar el papel que juega estas categorías. Para un estudio preciso sobre la noción de "principios jurídicos, cf. L. Vita, "La noción de principios jurídicos en la teoría del derecho de Hermann Heller" en Isonomía, $\mathrm{N}^{\circ} 43$, 2015, pp. 49-75.

48 H. Heller, Teoría del Estado, op. cit., p. 77. su capacidad de actuar como una unidad a través del derecho positivo. De ahí que una de las consecuencias de apoyarse en la episteme sociológica sea que el Estado adquiera un carácter reflexivo. Consciente de su carácter contingente, el Estado se apoya en su estructura (capacidad de actuar como una unidad por la vía del derecho) para intentar adaptarse a la constante irrupción de la novedad: "el Estado es algo que deviene; pero tampoco se puede desconocer que el Estado da forma a este devenir político”. El Estado es así objeto y actor de la historia, producto y productor de cambios sociales.

Dentro de este marco, la sociología jurídica se revela como un saber político fundamental en tanto es capaz de iluminar algunos aspectos esenciales de este régimen temporal. La sociedad con su carácter plural y conflictivo se organiza mediante el orden normativo del derecho, pero al no identificarse plenamente con él, siempre queda un espacio para que emerja la tensión productiva que permite regular la permanencia y el cambio. Ese justamente en esta dinámica donde emerge "el problema fundamental de toda sociología del derecho y del Estado", es decir "la cuestión de la relación entre normalidad y normatividad" ${ }^{\text {". }}$ Si, como afirma Heller "la política es el arte de traducir tendencias sociales en formas jurídicas", la sociología jurídica y sus categorías, al situarse en los intersticios de esta relación, ofrece una perspectiva que permite hacer inteligible estos procesos y darles una significación. De esta manera Heller reformula el planteamiento de Ehrlich al asignarle un papel fundamental en la coordinación de la pluralidad social a la dinámica que se establece entre la relativa autonomía del derecho y los grupos sociales.

En este sentido podemos afirmar que en el dispositivo helleriano la sociología jurídica ocupa el lugar de la moderna razón de Estado. Esto es perceptible cuando Heller argumenta a favor de un derecho moral de resistencia, interpretándolo como un recurso de última instancia que permite mantener abierta la tensión productiva entre positividad (estatal) y normatividad (social). En efecto, si bien Heller admite la imposibilidad lógica de legislar sobre un derecho de resistencia de carácter positivo en tanto implicaría liquidar la fundamental relación entre el derecho y Estado, lo reivindica como parte esencial de la moral del ciudadano democrático. Bajo circunstancias extremas, este derecho de resistencia puede funcionar como reaseguro de la relación conflictiva entre la sociedad y derecho. De ninguna manera la tensión que puede surgir entre el pluralismo social y Estado debe ser resuelta por la fuerza pues eso significaría disolver la dimensión normativa del derecho. Evitar esta interdicción debe movilizar toda la energía de la política y sus saberes prácticos, incluyendo la sociología jurídica: "La seguridad jurídica (ofrecida por el Estado) y la juridicidad (validez del derecho) pueden entrar en conflicto, y es cabalmente esta relación polémica la que plantea una problemática sustancial de la justificación del Estado concreto" ${ }^{\prime 50}$.

\footnotetext{
$49 \quad$ Ibidem, p. 322

so $\quad$ Ibidem, p. 286.
} 


\section{Conclusiones}

Hemos intentado mostrar que el adecuado esclarecimiento de la perspectiva sociológica desde la cual Heller ensaya su reformulación de la teoría del Estado resulta fundamental en la interpretación del dispositivo que bosqueja. Desde esta perspectiva, consideramos correcto afirmar que la emergencia de una sociedad propiamente política conformada por una pluralidad de grupos que establecen entre ellos relaciones tan conflictivas como interdependientes conduce a una sociologización de la política. En efecto, en el dispositivo helleriano la política queda reinterpretada como una praxis social que tiene como objeto la constante elaboración y reelaboración de estas relaciones plurales y conflictivas que se ubican en la sociedad. El fin de la política es la organización de la sociedad y el objetivo de la política estatal es darle un contenido normativo concreto a la cooperación de las relaciones sociales. ${ }^{51}$ Desde la perspectiva de una concepción política de los saberes modernos esta cuestión resulta un aspecto fundamental que debe conducir a una nueva ciencia política capaz de sostener la práctica de la política democrática.

\section{Bibliografía}

Caldwell, P. C., Popular sovereignty and the crisis of German constitutional law: the theory \& practice of Weimar constitutionalism, Duke University Press, 1997.

Callegaro, F., "Hegel precursore della sociologia? forza e limiti di un'alternativa filosofica alle scienze social” en Etica \& Política, Vol. XVIII, 2016, pp. 243-273.

-, “Une réaction à la Réaction. Les sciences sociales et l’héritage révolutionnaire” en Conceptos Históricos, Nº6, 2019, pp. 190214.

Carrino, A., "The Rebirth of Legal Philosophy within the Frame of Neo-Kantianism" en E. Pattaro. y C. Roversi, $A$ Treatise of Legal Philosophy and General Jurisprudence, Vol. 12, Netherlands, Springer, 2016, pp. 13-132.

Cavallo, R., "La critica al formalismo giuridico nel pensiero di Hermann Heller", en Quaderni Fiorentini, N 39, 2010, pp. 405435.

Cole, G. D. H., La organización política, México, Fondo de Cultua Económica, 1974.

Costa, P., "Lo Stato Sociale como problema storiografico" en Quaderni Fiorentini, N 46, 2007, pp. 41-102.

Dyzenhaus, D., "Kelsen, Heller and Schmitt: paradigms of sovereignty thought" en Theoretical Inquiries in Law, 16(2), 2015, pp. 337-366.

-, Legality and Legitimacy: Carl Schmitt, Hans Kelsen, and Hermann Heller in Weimar

Ehrlich, E., Fundamental principles of the sociology of law, New York, Routledge, [1916] 2000.

Freyer, H., La sociología, ciencia de la realidad, Buenos Aires, Losada, 1944.

Galli, C., Genealogía de la política. Carl Schmitt y la crisis del pensamiento político moderno, Argentina, UNIPE, 2018, pp. 371554.

Gay, P., The dilemma of democratic socialism: Eduard Bernstein's challenge to Marx, Collier Books, 1962.

Heller, H., "El sentido de la política", en El sentido de la política y otros ensayos, Valencia, Pre-Textos, 1996.

-, "Europa y el fascismo" en Escritos políticos, Madrid, Alianza, 1985.

-, “Socialismo y nación” en Escritos políticos, Madrid, Alianza, 1985.

-, "Democracia y homogeneidad social" en Escritos politicos, Madrid, Alianza, 1985.

-, Teoría del Estado, México, Fondo de Cultura Económica, 1942.

Herrera, C. M., "Kelsen y el socialismo reformista" en Revista de estudios políticos, N 96, 1997 pp. 77-115.

Jiménez Colodrero, A., "La crítica de Hermann Heller a la teoría de la personalidad estatal de G.W. F. Hegel" en Cuadernos de filosofía, $\mathrm{N}^{\circ} 67-68,2017$.

Kantorowicz, H., "Rechtswissenschaft und Soziologie" In Verhandlungen des 1. Deutschen Soziologentagesvom 19. bis 22. Oktober 1910 in Frankfurt am Main, 1969, pp. 275-310.

-, La lucha por la Ciencia del Derecho, Buenos Aires, Olejnik, 2018.

Karsenti, B., De una filosofia a otra. Las ciencias sociales y la politica de los modernos, San Martín, UNSAM Edita, 2017.

Kelsen, K., Teoría pura del derecho, Buenos Aires, Eudeba, 1999.

Lepsius, O., "Die Wiederentdeckung Weimars durch die bundesdeutsche Staatsrechtslehre", en Ch. Gusy (ed.), Weimars lange Schatten - "Weimar" als Argument nach 1945, Baden-Baden, Nomos, 2003, pp. 354-394.

Luhmann, N., "Sistema jurídico y dogmática jurídica” Centro de Estudios Constitucionales, 1983.

López Pina, A., "Hermann Heller y España" en Heller, H. Escritos politicos, Madrid, Alianza, 1984.

Marín, S., "Los fundamentos sociales, políticos y jurídicos del Soziale Rechtsstaat. Una relectura de Hermann Heller" en Res publica, 25, 2011, pp. 151-175.

-, "Estudio introductorio" en El derecho político de la Segunda República, Madird, Universidad Carlos III, 2011.

McCormick, J.P., "Max Weber and the Legal-Historical Ramifications of Social Democracy" en Canadian Journal of Law \& Jurisprudence, $\mathrm{N}^{\circ} 17,2004$, pp. 143-184.

Monereo Pérez, J.L., "Fascismo y crisis política de Europa: crítica del Fascismo en Hermann Heller” en ReDCE, nº 7, 2007, pp. 379-420.

Stolleis, M., Public law in Germany, 1800-1914 en Berghahn Books, 2001.

Treves, R., "Sociología del Derecho y sociología de la idea de justicia en el pensamiento de Hans Kelsen", Cuadernos de la Facultad de Derecho, № 8, 1984.

Van der Linden, H., Kantian ethics and socialism, Hackett Publishing, 1988.

51 H. Heller, "El sentido de la política" en El sentido de la política y otros ensayos, Valencia, Pre-Textos, 1996, p. 57. 
Van Klink, B., "Facts and Norms: The Unfinished Debate between Eugen Ehrlich and Hans Kelsen" in Hertogh, M. (ed.), Living Law: Reconsidering Eugen Ehrlich, Hart Publishing, Oxford, 2009, pp. 127-156.

Verdú, L., "Socialismo y derecho constitucional" en Sistema N 17/18, 1977.

Vinx, L., Pure Theory of Law: Legitimacy and Legality, Oxford University Press, 2007.

Vita, L., "La noción de principios jurídicos en la teoría del derecho de Hermann Heller" en Isonomía No. 43, 2015 , pp. 49-75.

Weber, M., "On Legal Theory and Sociology" [1911] en A. Jacobson y B. Schlink, "Weimar. A Jurisprudence of Crisis", University of California Press, 2000. 